\title{
When consent doesn't work: a rights- based case for limits to consent's capacity to legitimise
}

Article

Accepted Version

Hyams, K. (2011) When consent doesn't work: a rights-based case for limits to consent's capacity to legitimise. Journal of Moral Philosophy, 8 (1). pp. 110-138. ISSN 1745-5243 doi: https://doi.org/10.1163/174552411X549417 Available at https://centaur.reading.ac.uk/29828/

It is advisable to refer to the publisher's version if you intend to cite from the work. See Guidance on citing.

To link to this article DOI: http://dx.doi.org/10.1163/174552411X549417

Publisher: Brill

All outputs in CentAUR are protected by Intellectual Property Rights law, including copyright law. Copyright and IPR is retained by the creators or other copyright holders. Terms and conditions for use of this material are defined in the End User Agreement.

$\underline{\text { www.reading.ac.uk/centaur }}$ 
Central Archive at the University of Reading

Reading's research outputs online 


\section{When Consent Doesn't Work:}

\section{A Rights-Based Case for Limits to Consent's Capacity to Legitimise*}

\section{Keith Hyams}

Central to many of the most violent clashes fought on the battleground of consent are disagreements about the conditions under which consent is rendered ineffective. A clearer understanding of these conditions, of the limits to consent's capacity to legitimise, is key to unravelling the foundations of liberal morality and its attendant conflicts. Such an understanding promises significant contributions to enduring worries about moral constraints on the market and about the justification of political authority. Beyond this, questions about the conditions under which consent is rendered ineffective are central to many other prominent debates. When is consent to sex effective? How must doctors go about obtaining the consent of their patients if they are to ensure that such consent is effective? Can one consent to be killed and, if so, in what circumstances?

The literature on consent is replete with assertions about limits to consent's capacity to legitimise. Such assertions, based as they are on contested intuitions, lead us into a maze of disagreement with no obvious way out. In order to tidy up these intuitions

\footnotetext{
* For helpful discussion of earlier versions of this article I thank Jerry Cohen, John Gardner, Véronique Muñoz-Dardé, Michael Otsuka, Hillel Steiner, Andrew Williams, Jo Wolff and two anonymous referees.
} 
and to navigate a course to greater clarity, we need to uncover the deeper moral principles on which these intuitions are based.

\section{WHAT CONSENT IS}

Before we launch into an investigation of the grounds of limits to consent's capacity to legitimise, it may be helpful to begin with a few more general comments about the understanding of consent with which I shall be working. Consent is an act, an intentionally performed behaviour that may take the form of either an action or an omission. Examples of consent by action include the signing of a contract and the uttering of the words, 'Yes, go ahead', in response to a doctor's asking whether he may stick a needle in you. An example of consent by omission is consenting to a chairperson's proposal in a meeting by not speaking up when asked by the chairperson whether there are any objections. The presence of consent does require, in addition to an act, that certain psychological conditions be fulfilled, most importantly that the consenting agent knows that her act will count as an act of consent. But unlike subjective views of consent, my view does not regard the fulfilment of psychological conditions as sufficient for consent without the performance of a relevant act. ${ }^{1}$

Acts of consent can bring about changes. In morality, consent allows agents to change their rights, and the duties that correlate to them. Consent legitimises by changing rights: when an agent consents, she either waves her rights and grants liberties to another 
agent, or she waives her liberties and grants rights to another agent, or she does both of these things. ${ }^{2}$

It is worth noting that consent does not only operate in morality. We are familiar with consent's role in law. ${ }^{3}$ But consent is also used in other systems of rules. For example, when playing the board game Monopoly, one may consent to the exchange of a property that one has purchased for another player's property. Such consents do not have moral or legal implications. Rather, they have implications for the future course of the game. Nevertheless, although consent can operate in prescriptive systems other than morality, it is consent's role in morality with which we shall be primarily concerned, since it is in the theatre of morality where liberalism's perennial battles are fought.

Let us now turn to the main concern of this paper: limits to consent's capacity to legitimise. I will begin by setting out some of the disagreements that exist about these limits, in order to support the claim that we are in need of a theoretical grounding with which to chart a course through these troubled waters.

\section{SOME DISAGREEMENTS ABOUT LIMITS TO CONSENT'S CAPACITY TO LEGITIMISE}

\section{Procedural Limits}

We can divide limits to consent's capacity to legitimise into two types. The first type of limit is the procedural limit. Procedural limits demand that, in order successfully to legitimise other agents' actions and claims, consent must be given in the absence of 
certain background conditions. It will be useful to consider procedural limits under three headings. Under each of these headings, various types of deficiency, levels of deficiency, or deficiencies with particular geneses have been thought to render consent ineffective. But whilst there is agreement that at least some such deficiencies can render consent ineffective, there is widespread disagreement over which particular forms, levels or geneses of deficiency render consent ineffective.

\section{i. Alternatives}

It is often thought that an agent's consent fails to legitimise if the agent's alternative options to consenting are deficient in some specific way. The most widely affirmed of such claims is the claim that when an agent's option set is manipulated by another's coercive threat, such that the agent has no better alternative than to consent, then the coerced agent's consent is ineffective. But even here there are disagreements. It is sometimes thought that the option set resulting from the coercive threat must satisfy a more demanding criterion than merely making consent the best option, in order for the coercive threat to render consent ineffective. That, for example, the threat must leave the agent with alternatives, all of which are considerably worse than consenting; or that the threat must leave the agent with a choice structure that entitles her to accede to the threat, in order for the agent's consent to be rendered ineffective. Further disagreements arise over precisely what sort of threats can render consent ineffective. If an agent A, whose set of options has been appropriately constrained, consents in order to avoid B's carrying out a threat to bring about an undesirable outcome, is this sufficient to render A's consent ineffective? Or is A's consent rendered ineffective by B's threat only if B threatens to 
bring about an undesirable outcome by acting immorally? If the latter, do any such threats render consent ineffective, or only threats to violate rights? Can certain types of offer coerce, in a manner which renders consent ineffective? ${ }^{4}$

Coercive threats (and perhaps offers) are not the only method by which an agent's option set can be made deficient in a manner sometimes thought to render consent ineffective. It is also sometimes claimed that if an agent's option set was significantly impoverished because of some earlier wrongdoing, consent is ineffective. For example, if I push you down a hole, it seems plausible that your subsequent consent to pay me one million pounds to lower down a rope by which you could climb out of the hole is ineffective. ${ }^{5}$ Hume famously complains, against Locke's theory of tacit consent, that the claim that 'a poor peasant or artisan has a free choice to leave his country when he knows no foreign language or manners, and lives from day to day, by the small wages which he acquires' is as absurd as the claim 'that a man, by remaining in a vessel, freely consents to the dominion of the master; though he was carried on board while asleep, and must leap into the ocean, and perish, the moment he leaves her'. ${ }^{6}$ Indeed, it is sometimes even claimed that prior wrongdoing is unnecessary to render consent ineffective; that when an agent suffers from an absence of acceptable alternatives, even when the genesis of her situation involves no wrongdoing on anyone's part, her consent is rendered ineffective. ${ }^{7}$

\section{ii. Information}

In order for an agent's act to count as consent, the agent must know both that her act counts as an act of consent, and to what her act counts as an act of consent (unless her ignorance is negligent). But beyond this, informational deficiencies of other types are 
often thought to render consent ineffective: deficiencies such as the absence of true information, or the presence of false beliefs, which have to do with the background context in which consent is given or with the likely consequences of the consent.

Among intuitions of this type, perhaps the most widely held is the intuition that fraudulent claims made by the recipient of an act of consent can sometimes render consent ineffective. (I will refer to the agent to whom consent is given as the recipient.) But there are still disagreements with respect to further questions. If the recipient did not actively lie, but simply omitted to pass on relevant information, can this suffice to render consent ineffective? For example, if a company selling a special strain of maize seeds to farmers fails to tell the farmers that, unlike normal maize seeds, their seeds will strip the earth of its nutrients and render the land uncultivable within five years, is the consent of those farmers who purchase the seeds rendered ineffective by this failure? Does it matter whether the recipient knew that the information he was passing on was false, and if he didn't, does it matter whether he was negligent in not knowing that the information was false? Can false information from sources other than the recipient render consent ineffective?

\section{iii. Competence}

Under the heading of competence, it is widely thought that conditions which compromise an agent's ability to make rational decisions, conditions such as youth, mental incapacitation, psychosis and intoxication, can render consent ineffective. Once again, however, disagreement is never far away. One group of disagreements concern the questions, what degrees of youth, incapacitation, psychosis, intoxication and so on are 
required to render consent ineffective? Another group of disagreements are concerned with responsibility. It is widely agreed that consent is ineffective if the recipient of the consent maliciously caused the incompetence - if, for example, he forcibly injected the consenting agent with some intoxicating drug immediately prior to her consent. But what if the consenting agent was fully aware and responsible for her own intoxication, or other form of incompetence? Should her consent be taken as effective? Voluntary intoxication does not generally serve to release those who commit crimes from taking responsibility for their crimes, so should it similarly fail to free those who consent from taking responsibility for the consequences of their consent?

Even if one thinks that in cases such as voluntary intoxication by recreational alcohol consumption, voluntarily induced incompetence sometimes does not render consent ineffective, there are nevertheless other cases of voluntarily induced incompetence which certainly do seem to render consent ineffective. For example, suppose that an agent is taking consciousness-impairing drugs necessary to suppress some serious illness, or that she is regaining consciousness after an operation under general anaesthetic. In such cases, her consent (to all but the most urgent or frivolous of matters) would seem to be ineffective, despite the fact that she voluntarily rendered herself incompetent, or voluntarily allowed herself to be rendered incompetent. One might object that her impaired consciousness was rendered involuntary by the fact that she needed to have her consciousness impaired in order to escape the consequences of her illness or to undergo the operation. But it seems plausible to assert that her consent would be equally ineffective if the operation for which she had been anaesthetised was beautyenhancing plastic surgery. 
Substantive Limits

The second type of limit to consent's capacity to legitimise is the substantive limit. Whereas procedural limits are concerned with the background conditions under which consent is given, substantive limits are concerned with what the consenting agent is seeking to legitimise.

Disagreement about substantive limits is every bit as deep seated as disagreement about procedural limits, if not more so. Can one effectively consent to be killed? If yes, can one always effectively consent to be killed, or only in certain special circumstances? Can one effectively consent to be tortured? Can one, to bring into focus the difficult question faced by the court in the 2003-4 headline trial of the German cannibal, Armin Meiwes, whose victim was willingly eaten, effectively consent to be eaten ${ }^{8}$ There is also disagreement about the extent and details of the interaction between procedural and substantive limits. Certain procedural limits only seem to 'kick in' when the stakes are sufficiently high. For example, if a little girl consents to purchase a small chocolate mouse for an appropriate price, we would treat her consent as effective. But if she consents to surgery, we might consider her consent ineffective without the further consent of her parents. And if she consents to sex, we might consider her consent ineffective even with the further consent of her parents. But there will be widespread disagreement about the age at which the girl becomes competent enough to decide to consent on these various matters, reflecting disagreement not only about how competent the girl is at various ages, but also about the level of competence required for consent to legitimise different things. ${ }^{9}$ 


\section{THE INSUFFICIENCY OF PATERNALIST EXPLANATIONS}

As the preceding comments suggest, intuition provides inadequate guidance in discerning limits to consent's capacity to legitimise. Whilst there are a handful of widely agreedupon limits, there are many more disputed limits of varying scope. In order to reach firmer conclusions about limits to consent's capacity to legitimise, we need to identify the deeper sources of disagreement by considering why there should be any limits placed on consent's capacity to legitimise at all. That is, we need to explain the existence of the intuitions discussed above by showing how they manifest deeper moral principles.

Where existing discussions of limits to consent's capacity to legitimise do go beyond mere assertion, they tend to argue that limits to consent's capacity to legitimise exist in order to benefit agents by preventing agents from making ill-considered decisions to consent when it will likely harm them to do so. Such explanations are paternalist in nature: they suggest that morality incorporates these limits in order to protect us from ourselves. Paternalist explanations implicitly appeal to a deeper moral principle, according to which prescriptions that appropriately benefit agents should be included in morality, or at least in a relevant subset of morality. (Which is not to say that any explanation that appeals to such a principle is paternalist: paternalism requires, additionally, that the explanation claims that a moral prescription benefits agents by overruling their own decisions, for their own sakes).

Paternalist explanations of this nature are, of course, somewhat controversial. The controversy surrounding paternalist explanations of limits to consent's capacity to 
legitimise arises both out of disagreements about the legitimacy of the deeper principle, and out of disagreements about how likely agents are to make poor decisions for themselves. Among those who accept some version of the deeper principle, those who think that agents are quite likely to make poor decisions for themselves will favour a wider set of paternalist limits, whereas those who think that agents rarely make poor decisions to consent will favour a more restricted set of paternalist limits. Precisely because of these controversies, a paternalist explanation seems well equipped to explain several of the disagreements about intuitive limits to consent's capacity to legitimise. The disagreements at the intuitive level arise from disagreements about quite how extensive a set of paternalist limits are necessary to protect agents against themselves, and whether agents should be protected against themselves at all.

But a paternalist explanation of limits to consent's capacity to legitimise is insufficient, on its own, to explain all our intuitions about limits to consent's capacity to legitimise. I will argue that although paternalism provides a helpful explanation of some of our intuitions about limits to consent's capacity to legitimise, we need to find a different explanation for other of our intuitions about the limits. For when we consider what types of limit can be explained by paternalist reasoning, we find that paternalist reasoning is well placed to explain certain types of limit, but not others. On the one hand, paternalist reasoning seems well placed to explain substantive limits and procedural limits associated with incompetence. But on the other hand, paternalist reasoning seems poorly equipped to explain limits associated with the availability of alternative options and information. Let us look at these successes and failures in turn. 
First, paternalist reasoning is well suited to the explanation of several intuitions about substantive limits to consent's capacity to legitimise, like the putative limit preventing agents from consenting to be tortured. Such intuitive limits can be explained by paternalist considerations as preventing agents from consenting to things which are never, or extremely rarely, beneficial for them. Procedural limits associated with incompetence can also be explained by paternalist considerations as protecting agents who, because of their incompetence, are likely to make poor decisions to consent. Furthermore, paternalist reasoning lends itself to an explanation of the intuition that the level of competence demanded in order for an agent's consent to be effective varies depending on what is at stake.

On the other hand, a paternalist explanation struggles to explain those procedural limits associated with lack of choice and with lack of information. ${ }^{10}$ In the case of lack of choice, an agent is no more likely to make a poor decision to consent when he lacks a good option set than when he doesn't. An agent with a restricted option set might not relish the prospect of consenting, but if he still judges the option of consenting to be his best option then the mere fact that his choice is restricted is not a reason to impugn his judgement. In the case of lack of information, one might make a paternalist case for treating consent as ineffective when it is given without sufficient information or with mistaken beliefs in general. The paternalist grounds for such a limit would be that consent based on insufficient information or mistaken beliefs is more likely to be a poor decision than a decision based on more complete information and true beliefs. But we do not in fact tend to treat consent given in the absence of full information as ineffective in general. Rather, our intuitions on this matter are sensitive to the source of the 
informational deficiencies. In particular, we tend to think that consent is rendered ineffective when information is deliberately withheld, or false information deliberately supplied, but not when the informational deficiencies are the consenting agent's own fault. And it is hard to see how a paternalist approach could explain these intuitions, since the source of false or incomplete information has little bearing on the likelihood that an agent will make a poor decision to consent in the light of it.

Most problematically, paternalist considerations seem unable to explain why, according to some of our strongest intuitions about procedural limits to consent's capacity to legitimise, an important factor in determining whether consent is rendered ineffective often seems to be whether or not the consenting agent's rights have been violated or threatened with violation. Several of the most strongly held intuitions about procedural limits to consent's capacity to legitimise discussed above suggest that rightsviolations, or threatened rights-violations, often serve to render consent ineffective. Indeed, this intuition is shared even by libertarians, who rank transactions vitiated by rights violations alongside theft, as a method of transfer that fails to preserve just entitlements. If we can explain this intuition then we will have justified a central part of the libertarian theory of justice.

It would appear, then, that although paternalist considerations can explain some of our intuitions about limits to consent's capacity to legitimise, they cannot explain all of them. In order to explain those of our intuitions about procedural limits that suggest that violations or threatened violations of rights can render consent ineffective, I will argue in the following sections that we must appeal to principles of corrective justice concerning the legitimacy of gains and losses brought about by violations and threatened violations 
of rights. The background of corrective justice is central to understanding the logic of rights, which in turn is necessary for an adequate understanding of consent. As I noted above, consent's role in morality is to change rights. We can therefore only understand how consent works if we do so alongside the logic of rights and its associated norms, including those of corrective justice. Note, however, that the appeal to corrective justice is not intended to replace the paternalist explanation, which I argued does succeed in explaining some of our intuitions about limits to consent's capacity to legitimise. Rather, the appeal is intended to supplement the paternalist explanation, in order to account for those our own intuitions about procedural limits to consent's capacity to legitimise which, as noted, a paternalist approach is unable satisfactorily to explain.

In the following section, I will state and defend the principles of corrective justice that I will ultimately use to explain limits to consent's capacity to legitimise.

\section{THE NO-GAIN AND NO-LOSS PRINCIPLES}

Rights place restrictions on what agents may and may not do to each other and each other's property. But what if, despite the existence of rights, agents do in fact treat each other, or each other's property, in ways that are prohibited by their rights? When an agent A violates the rights of another agent $\mathrm{B}, \mathrm{A}$ might gain as a result of the violation and $\mathrm{B}$ might suffer losses. These consequences of rights-violations, even when unintended or accidental, are illegitimate. As such, we seek to nullify the consequences by demanding compensation from the perpetrator to the victim and by demanding rectification of any property gained as a result of the violation. Similarly, when an agent extracts some gain 
from another agent by threatening to violate the other's rights, we also demand compensation and rectification. According to the annulment conception of corrective justice, norms of compensation and rectification are expressions of the following two principles:

The no-gain principle: The perpetrator of a rights-violation or threatened rights-violation should not gain as a result of his violation or threatened violation of another's rights.

The no-loss principle: The victim of a rights-violation or threatened rightsviolation should not suffer losses as a result of the violation or threatened violation of his rights.

What counts as a gain or a loss in the above two principles? There are various types of gain or loss about which we might ultimately be concerned. Gains and losses of property, of welfare, of opportunities for welfare, of freedom. The gains and losses about which one will ultimately be concerned will depend on what one thinks is the purpose of rights - what precisely it is that rights exist to protect or promote. But we need not choose between these ultimate concerns in order to pursue the argument here. The main argument of this paper, which claims that the no-gain and no-loss principles can explain limits to consent's capacity to legitimise, will require us to accept that gains and losses of rights and liberties (as opposed to violations of rights) are themselves gains and losses of a type relevant to the no-gain and no-loss principles. Whatever our ultimate concerns, it is clear that this must be so. For if rights and liberties are not themselves either intrinsically valuable moral assets, or instrumentally valuable moral assets (because they protect 
welfare, opportunities, freedom, or so on), then we should have no reason to be concerned about their violation, and to seek corrective justice. If we care about violations of rights - which we do - then we must also care about gains and losses of rights and liberties, for the same ultimate reasons in both cases. ${ }^{11}$

Note that the gains and losses are to be measured relative to what would have obtained had the violation or threat not occurred, not relative to what obtained immediately prior to the violation or threat. This is why, for example, intuition suggests that the victim of a violent assault can claim compensation not only for the pain that the assault inflicted on him, but also for the lost earnings which he would have earned had he not been prevented from going to work because of his injuries.

Before we continue with the main thread of the argument, we first need to defend the no-gain and no-loss principles against an important objection. On the strength of the objection, Jules Coleman, who once defended the annulment conception of corrective justice, now rejects the annulment conception in favour of an alternative view. ${ }^{12}$ The objection is this. Building on criticisms put to the annulment conception by Raz, Weinrib and Perry, Coleman argues that the annulment conception cannot account for the special relationship that exists between the perpetrator and the victim of a particular crime. The no-gain and no-loss principles do not require that the victim of a crime receive compensation from the perpetrator of that very same crime. The principles would, for example, be satisfied by a system in which perpetrators paid into a common pool from which victims received compensation. Yet intuitive norms of compensation do require that a victim be compensated by the perpetrator of the very same crime that harmed her, not by perpetrators of other crimes. Hence, the argument claims, a perpetrator's duty to 
repair wrongful losses inflicted on his victim do not arise from the fact that the losses are the result of a wrongdoing, as the annulment conception claims.

In the face of the special relationship between perpetrator and victim, Weinrib has argued for what Coleman calls a 'relational conception' of corrective justice, according to which corrective justice imposes on a perpetrator a duty to repair his wrong. ${ }^{13}$ Coleman himself has adopted a variation on this, which he calls the 'mixed conception'. According to the mixed conception, a perpetrator has a duty to repair wrongful losses inflicted on his victim, the duty being grounded in the fact that the losses are the injurer's responsibility, the result of his agency. The conception is 'mixed' in that it combines the relational view that the duty to repair is grounded in the responsibility of the perpetrator rather than the wrongfulness of the losses, with the annulment view that it is the wrongful losses that are to be repaired rather than the wrong itself.

We need not reach a view about the truth or falsehood of the relational conception, the mixed conception, or any other similar view. The main argument of this paper does not depend on these views being false. What it does depend on, however, is the no-gain and no-loss principles being true. The assumption underlying Coleman's rejection of the no-gain and no-loss principles is that either the annulment conception must be true, or an alternative view such as the relational or mixed conception must be true. But this assumption is mistaken. We can consistently endorse both the no-gain and no-loss principles, and something akin to the relational or mixed conception. Indeed, not only can we endorse both positions, we should endorse both positions. For as much as we need something like the relational or mixed conception to explain the special relationship 
between perpetrator and victim, so too do we need the no-gain and no-loss principles to explain our intuitions about the following additional cases.

The first problem concerns our intuitions about what should happen when a perpetrator is unable to compensate his victim for her losses. In at least some such circumstances, intuition suggests that the victim still deserves compensation for her losses, perhaps from the public purse. Those injured by suicide bombers, for example, seem to deserve some form of compensation for their injuries, even though their assailant is no longer able to pay (and, let us suppose, has left no estate from which payment can be made). This intuition can easily be explained by the no-loss principle. But the relational conception and the mixed conception cannot easily explain this intuition, because they provide no grounds for treating agents other than the perpetrator as under duties to compensate the victim, even when the perpetrator cannot pay.

The second reason not to abandon the no-gain and no-loss principles in the face of the special relationship between perpetrator and victim, is that we need the no-gain principle to explain why the perpetrator of a rights-violation ought to forgo even certain gains that do not correspond to his victim's wrongful losses. For example, suppose that a thief steals a fishing boat which has been lying idle in a harbour for several months. The thief takes the boat out to sea and catches many fish in it. The thief ought to return the boat to its owner and, if necessary, provide compensation to the owner for any losses incurred (for example, because the boat has been damaged). But in addition to this, the thief ought not to be allowed to keep the fish caught with the stolen vessel. This gain, which the thief is required to forfeit, is neither a part of the wrong itself nor corresponds to any wrongful loss on the part of the boat owner: the boat would otherwise have been 
lying idle in the harbour. As such, neither the relational conception nor the mixed conception can explain why the thief should give up the fish. The no-gain principle, on the other hand, provides an immediate explanation of why he should do so.

The foregoing considerations suggest that the no-gain and no-loss principles should not be abandoned in the face of the special relationship between perpetrator and victim. Rather, they should be supplemented by additional principles. These additional principles might be those endorsed by the relational or mixed conceptions, or something similar to them. But if we treat these additional principles as alternatives to the no-gain and no-loss principles rather than as supplementary to them, then we are unable, I have argued, to explain the following two intuitions. First, the intuition that the victim of a rights-violation can sometimes be owed compensation by agents other than the perpetrator of the violation. Second, the intuition that the perpetrator of a rights-violation ought sometimes to have his gains nullified, even when such nullification is not required to compensate his victim for her losses. In the face of arguments about the special relationship between perpetrator and victim, we should indeed conclude that the no-gain and no-loss principles alone do not suffice to provide a complete explanation of all aspects of compensation and rectification. But I have argued that there are good reasons to think that the no-gain and no-loss principles must provide an important part of such an explanation, and that we should not abandon them for an alternative view altogether. 


\section{ARE THE NO-GAIN AND NO-LOSS PRINCIPLES GROUNDED IN BENEFIT?}

We will shortly come to the main argument of the paper, in which we will see how the no-gain and no-loss principles can explain limits to consent's capacity to legitimise. But before we do so, I wish briefly to look at what might ground the no-gain and no-loss principles themselves, in order better to understand the relationship of the no-gain/no-loss explanation of limits to consent's capacity to legitimise to the paternalist explanation examined above. We saw that paternalist explanations for limits to consent's capacity to legitimise, which I argued do successfully explain some intuitive limits, rely on a deeper moral principle, according to which prescriptions that benefit agents in an appropriate manner should be included in morality, or at least in a relevant subset of morality. The question I presently wish to ask is, should we conclude that the no-gain and no-loss principles are also ultimately grounded in benefit-based considerations, so that the two explanations are in fact both different facets of the same ultimate benefit-based explanation of all limits to consent's capacity to legitimise?

In order to argue that the no-gain and no-loss principles exist in order to benefit agents, one would first need to show that they do benefit agents. So do the no-gain and no-loss principles benefit agents? Certainly, inclusion of the no-gain principle in morality benefits agents, since, provided that it is enforced, the no-gain principle removes an incentive for committing or threatening violations. If a would-be violator or coercer knows that society will, in accordance with the no-gain principle, seek to nullify any gains which he acquires as a result of his performing or threatening a violation, then he is 
much less likely to perform or threaten a violation than he would otherwise be. In other words, enforcement of the no-gain principle serves as a deterrent to would-be violators and coercers.

Does inclusion of the no-loss principle in morality also benefit agents? Inclusion of the no-loss principle in morality, even when it is enforced, is likely to have a much smaller deterrent effect on would-be violators and coercers than the no-gain principle. This is because, in the case of the no-gain principle, would-be violators and coercers who are motivated by a desire for personal gain are likely to perform or threaten violations, such as a theft, that bring about gains to themselves which can be entirely nullified (for example, by returning stolen items to their owner). But in the case of the no-loss principle, the sorts of losses brought about by violations or threats likely to be performed by would-be violators and coercers motivated by a desire to cause suffering to another agent, often cannot be so easily nullified. Such violations or threats are likely to result in physical harm that, even with the provision of monetary compensation, cannot be made to vanish in a way that denies the perpetrator the satisfaction of having caused the harm to his victim. Hence enforcement of the no-loss principle is unlikely to remove the incentive of a would-be violator or coercer whose motivation for violating or threatening to violate rights is to harm his would-be victim. More plausibly, one might argue that the no-loss principle benefits agents for the same reason that possession of rights benefits agents. Whatever it is that one thinks that rights exist to protect or promote - welfare, opportunities for welfare, freedom, etc. - one can plausibly argue that such benefits are protected and promoted not only by rights, but also by the assurance of compensation when rights are violated. 
So there is reason to think that the no-gain and no-loss principles might themselves be grounded in the benefit-based justificatory principle that underlies paternalist limits to consent's capacity to legitimise. But if these reasons fail to convince, if one thinks that the no-gain and no-loss principles are grounded in some alternative deeper principle, or if they are themselves fundamental principles of justice which cannot be explained by reference to further principles, then this conclusion does not threaten the arguments that follow. For even if the no-gain and no-loss principles are not grounded in the benefit-based justificatory principle that underlies paternalist justifications for limits to consent's capacity to legitimise, this need not prevent us from seeking to explain some limits to consent's capacity to legitimise in terms of the no-gain and no-loss principles. There is no reason why different justificatory principles should not ground different sets of limits to consent's capacity to legitimise. ${ }^{14}$

Let us now turn, then, to the main argument of this paper, in which I will demonstrate how the no-gain and no-loss principles can explain and tidy up central intuitions about limits to consent's capacity to legitimise.

\section{THE MAIN ARGUMENT: CONSENT, GAINS AND LOSSES}

How can the no-gain and no-loss principles justify limits to consent's capacity to legitimise? We have seen that when an outcome is brought about by a violation or threatened violation of rights, the no-gain and no-loss principles require that any gains and losses accruing to the perpetrator and victim respectively be nullified. When the 
outcome brought about by a violation or threatened violation is consent - let us call such consent, vitiated consent - we must therefore nullify any gains and losses resulting from the consent. So what are the gains and losses that result from consent? They are, of course, the gains and losses of rights and liberties associated with the act of consent.

In order to avoid confusion, it is important that we distinguish clearly between the two different roles played by rights in the argument. First, rights play a role in the genesis of vitiated consent: vitiated consent is consent brought about by a violation or threatened violation of rights. Second, rights play a role as the object of consent: effective consent changes agents' rights. The argument is that when consent is vitiated by a violation or threatened violation of rights, the no-gain and no-loss principles require us to nullify the gains and losses in rights and liberties that result from the consent.

How do we nullify the gains and losses in rights and liberties that result from vitiated consent? Quite simply, we treat vitiated consent as ineffective. If I consent to give a gunman my bicycle when he threatens to kill me, then my consent would be ineffective. Although I might physically hand over the bike, I would nevertheless retain both liberties to use the bike and rights against others' use of it, and the gunman would gain no such rights and liberties. Although the gunman would have physical control over the bicycle, morally he would have the same duty not to use the bike and not to interfere with my use of the bike that he had before he seized the bike. The gains and losses that would have resulted from the vitiated consent had it been treated as ineffective are thereby nullified. ${ }^{15}$ (Which is not to deny that additional action will be needed to nullify the gains and losses resulting from the seizure of the bike, but that is a separate matter.) 
One might object that there is an alternative way to nullify the gains and losses associated with vitiated consent, and that I have arbitrarily chosen the above method over this alternative. The alternative way would be to treat the consent as effective in changing rights and liberties, and then require a perpetrator to compensate his victim by consenting to return those rights and liberties, or by giving something of equal value to his victim instead. On this model, for example, if I consent to give a gunman my bicycle because he threatens to kill me if I don't, then the gunman would gain rights and liberties to use and to prevent others from using the bike, and I would lose these rights and liberties. The gunman would, however, have a duty to compensate me by consenting to return the rights and liberties to me, or by giving me something of equal value instead. Now it is true that this alternative would also succeed in nullifying the gains and losses brought about by vitiated consent, albeit in a much more roundabout manner than the previous way. But the point is that we are not here trying to justify new ways of dealing with the consequences of rights violations and threatened rights violations. Rather, our purpose is to explain and to tidy up our existing intuitions about limits to consent's capacity to legitimise, and in particular the intuition that consent brought about by a violation or threatened violation should in fact be treated as ineffective. My claim is that this intuition is best explained in terms of its nullifying the gains and losses brought about by the vitiated consent. That is, the intuition that consent brought about by a violation or threatened violation of rights is ineffective can, like norms of compensation and rectification, be explained as an expression of the no-gain and no-loss principles.

Note that either the no-gain or the no-loss principle would, on its own, provide sufficient ground to treat consent as ineffective. As such, consent should be treated as 
ineffective if either the consenting agent is the victim of a violation, or if the recipient is the perpetrator of the violation. It will often be the case both that the consenting agent is the victim of a violation, and that the recipient is the perpetrator of the violation; but where there is a third party involved and only one of these conditions is satisfied, we should still treat consent as ineffective. For example, in cases of what Steiner calls liberal exploitation, the recipient violates a third party's rights in order to secure an exchange with the consenting agent on favourable terms, without facing competition from the third party. Alan, for example, might say to Betty, 'I am going to offer Charlie $£ 3$ for his hammock. Don't you dare offer Charlie more than $£ 2$ for his hammock: if you do, I'll punch you!'. The no-gain principle can explain why consent in such cases should be treated as ineffective in terms of the need to prevent the recipient from gaining by his violation. ${ }^{16}$

\section{BRINGING ABOUT}

If the argument so far is right, that some intuitive limits to consent's capacity to legitimise can be explained as expressions of the no-gain and no-loss principles, then we can use this finding to begin to tidy up our intuitions, by determining exactly when consent should be rendered ineffective according to the no-gain and no-loss principles. In order to do so, an important question to be addressed is, when should we say that an act of consent is brought about by a violation or threatened violation of rights? What relation is required to exist between the violation or threat and the subsequent consent in order to 
trigger the no-gain and no-loss principles? The danger is that without clarifying when an act of consent is brought about by a violation, the use of the no-gain and no-loss principles to determine limits to consent's capacity to legitimise could yield absurd results. For example, suppose that, having been physically attacked in the street, a man returns home to his partner, shaken and upset. The man's partner embraces him and the embrace quickly leads to sex. Had the man not just been attacked, and had his partner not wanted to comfort him, neither the man nor his partner would have wanted to have sex that particular evening. Without clarifying when an act of consent is brought about by a violation, it might seem that the man's being attacked in the street brought about both the man's consent to sex and his partner's consent to sex; this would, according to the nogain and no-loss principles, give the absurd result that neither the man nor his partner had effectively consented to sex.

The problem of determining what normatively relevant relation must hold between an action and some consequence is not unique to the no-gain and no-loss principles. Any moral principles which attach relevance to how particular consequences were brought about must face similar difficulties. Consequentialists, of course, face this problem. As do luck egalitarians, who are concerned to establish whether or not a particular outcome was brought about by an agent's choice or not. In fact, anyone who endorses even a minimal set of crimes, even libertarians, will sometimes confront difficult questions about whether or not a particular agent's action should count as a crime on the basis that the action brought about a particular harm (or whether the action should count as one crime rather than another - manslaughter rather than reckless driving, for example). Despite the difficulties with which the relation is attended, a few 
comments might at least serve to provide some guidance in determining when consent is brought about by a violation or threatened violation and when, therefore, consent should be treated as ineffective in accordance with the no-gain and no-loss principles.

First, the relevant relation that must exist between the violation or threat and the consent does not require that the perpetrator intend to bring about the consent. Nor does the relevant relation require that the perpetrator foresee the consent, or even that the consent was a foreseeable result of the violation or threat. According to any plausible interpretation of the no-gain and no-loss principles, gains and losses can sometimes be considered illegitimate even if they occur entirely unexpectedly or accidentally, because of the violation or threat. Suppose, for example, that Jack is in a bad mood after falling half way down a hill. Jack's bad mood makes him aggressive, and when Jill comes to Jack's aid he promptly pushes her down the remainder of the hill. Unbeknown to both Jack and Jill, there is a concealed mineshaft at the bottom of hill which Jill, tumbling down the hill, falls into, suffering massive spinal injuries as a result. That Jack did not foresee that his pushing Jill down the hill would result in such a terrible outcome (indeed, he would never have pushed her had he realised) does not relieve Jack of the burden of compensating Jill for the losses she suffers as a result of her injuries.

One necessary condition for the applicability of the no-gain and no-loss principles is that the gain or loss was caused by the violation or threatened violation. But this still leaves us a long way from knowing when a gain or loss was brought about by a violation or threatened violation, in the sense required by the no-gain and no-loss principles. One reason for this is that there is widespread disagreement over what causation itself implies. Furthermore, since we are concerned with how the no-gain and no-loss principles apply 
to acts of consent brought about by a violation or threatened violation, we face special difficulties in analysing action causation. It seems likely that action causation cannot be analysed in the same manner as straightforward event causation, requiring instead a special analysis of how one agent provides or changes another agent's reasons for action. $^{17}$

More problematically still, even if the causation requirement is a necessary condition for an action's having some consequence in the normatively relevant sense, it certainly isn't a sufficient condition. On a non-normatively loaded understanding of causation, it might be true that one cause of the driver's running over the child was the brewing of the beer which the driver drank minutes before he ran over the child. Likewise another cause of the driver's running over the child might be that a woman whom the driver found particularly attractive happened to step out of a shop and catch his eye at just the moment the child stepped into the road. But neither the brewing of the beer nor the woman's stepping out of the shop brought about the road accident. The road accident was brought about by the driver's drink-driving.

In seeking to discover what brought about some consequence, we must work backwards down the various causal chains which jointly eventuated in the consequence of concern, until we reach some cause which has, in Hart and Honoré's terms, 'a special finality at the level of common sense'. ${ }^{18}$ What determines which cause has this special finality varies with the context and the nature of the causal chain under consideration, and one's reason for seeking an explanation of some consequence. When one's interest in seeking an explanation of some consequence is for the purpose of moral prescription, as when we seek to apply the no-gain and no-loss principles, normative considerations will 
certainly play a role in this determination. One suggestion made by Hart and Honoré which seems to me both substantially correct and which yields plausible results when we come to apply the no-gain and no-loss principles in what follows (though the arguments that follow do not depend on the truth of the suggestion), is that very often voluntary human action has this special finality. As Hart and Honoré put it, 'A deliberate human act is therefore most often a barrier and a goal in tracing back causes in such inquiries: it is often something through which we do not trace the cause of a later event and something to which we do trace the cause through intervening causes of other kinds. ${ }^{19}$

The suggestion that voluntary actions have a special place in explaining what brought about some consequence can serve to guide us in identifying cases of vitiated consent, cases in which consent is brought about by a violation or threatened violation of rights. The suggestion implies that a violation or threatened violation brings about an act of consent when it renders the consent involuntary. ${ }^{20}$ If a violation or threatened violation does not render an agent's consent involuntary, then the violation or threatened violation will not have brought about the consent in the relevant normative sense. For if the consent is voluntary, no further explanation would be required: the consenting agent's will would itself be a cause with the requisite finality to have brought about the consent and consequent gains and losses of rights or liberties.

Although we can be guided by the thought that a violation or threatened violation brings about consent only if it renders the consent involuntary, we cannot simply use this thought (together with the no-gain and no-loss principles) to fix limits to consent's capacity to legitimise, without further reference to our intuitions on the matter. We need our intuitive judgements to guide our understanding of voluntariness - and to confirm its 
relevance to limits to consent's capacity to legitimise - as much as we need the voluntariness principle to help us secure our intuitions on the matter. This is not to say that we should create a logical circle whereby we explain our intuitive judgements in terms of a notion of voluntariness which is itself justified by reference to those intuitive judgements. Rather, it is to say that both our intuitive judgements and our understanding of voluntariness have some independent purchase, but that the independent purchase of both is insufficiently clear in places, so that we require reference to the other in order to emerge with a satisfactory account of limits to consent's capacity to legitimise. By pursuing this approach we will emerge with an account that does justice both to our contested intuitions and to the deeper theoretical framework of the no-gain and no-loss principles.

Let us look, then, in the following section, at the various ways in which violations and threatened violations can bring about consent. In doing so, we will see how the nogain and no-loss principles can explain many of our central intuitions about procedural limits to consent's capacity to legitimise.

\section{WHAT THE NO-GAIN AND NO-LOSS PRINCIPLES TELL US ABOUT PROCEDURAL LIMITS}

The principal ways in which a violation or threatened violation intuitively can bring about an act of consent correspond closely to the three headings under which I said intuitive procedural limits to consent's capacity to legitimise could be grouped. It seems plausible to regard these as the three ways in which the agent's consent can be rendered 
involuntary, so that the violation or threatened violation, rather than the consenting agent's own will, is the cause with the relevant special finality. The three ways are as follows. First, one might bring about another's consent by altering her set of options in a manner that leads her to consent. Second, one might bring about another's consent by altering or failing to alter those of an agent's beliefs upon which her decision to consent was partly based. And third, one might bring about another's consent by altering her mental state, such that the agent consents without making a reasoned decision to do so, on the basis of the options and information available to her. That the no-gain/no-loss approach to the explanation of such intuitive limits is able to explain where these three headings come from is a point in its favour, a reason to accept the explanation. Let us look at each in more depth to determine more precisely what limits to consent's capacity to legitimise are implied by the no-gain and no-loss principles in each case.

\section{i. Alternatives Revisited}

One of the most widely agreed-upon limits to consent's capacity to legitimise, the intuition that consent is sometimes rendered ineffective if given in order to avoid a threat to violate one's rights being carried out, can easily be explained by the no-loss and nogain principles. When an agent is coerced in this manner, his consent is rendered ineffective because it is brought about by a threat to violate his rights. The threat brings about the agent's consent by limiting the set of options from which he has to choose. But this limit is not the only intuitive limit to consent's capacity to legitimise which the nogain and no-loss principles can justify in the case of alternatives. A violation of an agent's rights, rather than a threatened violation, can also alter an agent's option set in a 
manner which brings about the agent's consent. When a violation of an agent's rights alters her option set so as to bring about her consent, the no-gain and no-loss principles require, in accordance with intuition, that her consent be treated as ineffective. This explains why your consent is ineffective in the example we looked at above, where I push you into a deep hole (a violation of your rights), then demand that you consent to pay me one million pounds to lower down a rope by which you may escape from the hole. Although you might physically hand over one million pounds in the hope that I might be satisfied with a physical transfer of the money, you cannot make it the case that I gain normative ownership of the one million pounds.

How must a violation or threatened violation alter an agent's set of options in order that the consent can be considered to have been brought about by the violation or threatened violation, rather than by the consenting agent's own will, in the manner required to trigger the no-gain and no-loss principles? It is insufficient merely to require that the violation or threatened violation provided a reason for the consent and thereby caused the consent - as we saw, even if causation is necessary, it is unlikely to be sufficient for normatively relevant bringing about. If one endorses the thought discussed above, that a violation or threatened violation brings about consent only if it renders consent involuntary, then the question becomes, how must the agent's option set be altered in order to render the agent's consent involuntary and thereby to rob the consenting agent's will of explanatory finality?

Various suggestions have been made as to how a violation or threatened violation must alter an agent's set of options in order that the consent can be considered to have been brought about by the violation or threatened violation. One such suggestion is that 
the violation or threatened violation must leave the agent with no alternative that is not considerably worse than the option to consent. ${ }^{21}$ But this suggestion seems somewhat implausible: why should it matter whether a violation or threatened violation leaves the agent with options that are considerably worse than consenting rather than options that are merely worse than consenting? A second suggestion is that, in order for consent to be rendered ineffective by virtue of its having been given in response to a coercive threat, the consenting agent must also be entitled to succumb to the threat. ${ }^{22}$ Again, this suggestion seems unsatisfactory, since it simply reframes the problem of determining when a threat brings about a violation in terms of determining when a consenting agent is entitled to succumb to the threat, leaving the substantive question about when such circumstances obtain wholly unanswered.

The most plausible answer to the question, how must a violation or threatened violation alter an agent's set of options in order for consent to be brought about by the violation or threatened violation, is that the consenting agent must be left with no reasonable alternative other than to consent. This proposal affirms the suggestion that consent is brought about by a violation or threatened violation when rendered involuntary, since the presence of a reasonable alternative might well be thought to be a prerequisite for voluntary action. There is much to be said, which I do not intend to say here, about what constitutes a reasonable alternative. But the proposal does seem to have a certain prima facie appeal. It can explain, for example, why Punch's consent to give Judy $£ 40$ when threatened with the alternative of having $£ 50$ forcibly stolen is ineffective, but why Punch’s consent to give Judy $£ 100$ when threatened with the forcible theft of $£ 50$ is not so obviously ineffective. It would be reasonable for Punch to hand over $£ 40$ in 
order to avoid the theft of $£ 50$, but it would not be reasonable of Punch to hand over $£ 100$ in order to avoid the theft of $£ 50$ (assuming no other harm is caused by the theft).

\section{ii. Information Revisited}

Violations and threatened violations of rights can bring about consent by affecting the beliefs of the consenting agent in a manner which leads her to consent, or by preventing the agent from obtaining information which would stop her consenting. For example, suppose that Harry's burning Sally's newspaper prevented Sally from discovering that the housing market had just crashed. Sally's subsequent consent to buy Harry's house at a price that she would not have agreed to if she had known about the crash is ineffective, since Sally's ignorance of the crash was brought about by Harry's violation of Sally's property right in the newspaper. Again, this seems to fit with the thought that a violation or threatened violation brings about consent only if it renders the consent involuntary, since one might plausibly regard consent in such cases as involuntary, or at least as not entirely voluntary. ${ }^{23}$

We have seen that an agent's consent can be rendered ineffective by a violation or threatened violation that alters an agent's beliefs or prevents her obtaining relevant information. But can an agent's consent also be rendered ineffective, as is often thought, just by another agent's conveying false information, or failing to convey true information to the agent? In determining whether any such limits can be justified by the no-gain and no-loss principles, the main problem is to determine which such conveyances or failures to convey count as violations of rights. The limits to consent's capacity to legitimise relating to the provision of false information or the withholding of true information 
depend on what rights to information one thinks that a consenting agent possesses. I shall consider three of the most common positions taken on this matter. I shall not seek to arbitrate between these three positions here, but this need not prevent us from exploring the implications of each position for limits to consent's capacity to legitimise.

The first position holds that agents in an agreement have neither rights that they be given true information nor rights that they not be given false information. According to this position, one cannot render consent ineffective either by withholding true information from a consenting agent or by providing false information to a consenting agent, since one's provision or withholding does not constitute a violation of his rights. Those who adopt this first position often claim that an agent's consent can only be rendered ineffective by another's provision of false information if the provider of the false information explicitly warrants his claims.

The second position holds that agents do sometimes have rights against misinformation, although they never have rights to any information. According to the second position, consent is not rendered ineffective by a failure to supply information, but consent can be rendered ineffective when an agent is provided with false or misleading information. Those who adopt this position need to specify how widely they intend the putative rights against misinformation to be interpreted: whether these rights can be violated and consent rendered ineffective when an agent is misled, or only when she is provided with false information. As Grice famously argued, a proposition does not need to be false in order to be misleading. ${ }^{24} \mathrm{~A}$ car salesman might, for example, tell a potential buyer that there may be a fault with the car he is seeking to sell, but dress up his disclosure as if it were just a disclaimer. What the salesman says is, strictly speaking, 
true. But it is misleading nevertheless. There is in fact a major fault with the car, and the salesman knows it. Those who adopt the second position also need to specify whether they hold that consent can only be rendered ineffective when an agent is intentionally provided with false or misleading information, or whether they think that consent can also be rendered ineffective when an agent is unintentionally but negligently (or even unintentionally and non-negligently) provided with false or misleading information.

The third position holds that agents have a right that certain relevant background information which might have a bearing on their decision to consent be given to them, if such information is possessed or could reasonably be obtained by those against whom the right is held. ${ }^{25}$ (Those who adopt this position usually think that agents also enjoy rights against misinformation.) Relevant background information might include, for example, information about a product that one proposes to buy, information about what the recipient of one's consent will do in return for the consent, information about the identity of the recipient, information about alternative options open to the consenting agent. According to this position, simply by withholding the relevant information, a recipient can render an agent's consent ineffective, since the consent will have been brought about by a violation of the consenting agent's right to information. But even if one thinks that the agent has a right to some relevant information, it is not always obvious what information she has a right to. For example, what duties of disclosure does a man have to a woman with whom he is seeking sexual relations? Does he have a duty to disclose that he has a sexually transmitted disease? Does he have a duty to disclose that he is married, or that he has been sleeping with his potential partner's sister? Does he have a duty to tell his potential partner that he isn't very good in bed? Those who adopt the third position 
need not hold that a consenting agent has a right to every possible piece of information which the recipient can reasonably provide, which might have a bearing on her decision to consent.

\section{iii. Competence Revisited}

The final way in which a violation or threatened violation can bring about an agent's consent is by rendering the agent mentally incompetent. For example, if Harry injects Sally with a drug, or threatens to punch her if she doesn't drink some intoxicating liquid which he offers her, then Sally's subsequent intoxicated consent to sleep with Harry is rendered ineffective by the role of the violation or threatened violation in bringing about her consent. Whereas violations and threatened violations which bring about an act of consent by way of alternatives or information alter what it is rational for the agent to do in the light of her options and beliefs, violations and threatened violations which bring about an act of consent by way of incompetence prevent the agent from deciding rationally to consent at all. Again, it seems plausible to regard this as a further way in which the consent can be rendered involuntary, in line with the suggestion that a violation or threatened violation brings about an act of consent when it renders the consent involuntary.

Note that although, as we have seen, paternalist considerations are well suited to explaining some of our intuitions about the conditions under which consent is rendered ineffective by incompetence, this does not preclude the possibility that the no-gain and no-loss principles might also explain further intuitions about when consent is rendered ineffective by incompetence. In particular, whereas paternalist considerations are well 
suited to explaining uncertain intuitions which suggest that consent is sometimes rendered ineffective by incompetence regardless of the cause of the incompetence, the no-gain and no-loss principles are better suited to explaining the relatively certain intuition that incompetence brought about by a violation or threatened violation renders consent ineffective. For example, paternalist considerations can explain the uncertain intuition which suggests that perhaps the consent to sex of a particularly intoxicated agent should be treated as ineffective. But it takes the no-gain and no-loss principles to explain the intuition that the consent to sex of a forcibly intoxicated agent should certainly be treated as ineffective.

Note also that the issue of what rights to information we have is relevant to the question, when is consent rendered ineffective by incompetence? Suppose, for example, that Sally is intoxicated by deception - perhaps Harry buys her a drink from the bar but slips in a drug before giving the drink to her. Whether or not Sally's subsequent consent is rendered ineffective by appeal to the no-gain and no-loss principle depends on whether or not the deception that led to Sally's intoxication was a violation of her rights. And whether the deception that led to Sally's intoxication was a violation of her rights depends on whether Sally had a right to be told that her drink had been spiked, or whether it was her own responsibility to determine the drink's content, perhaps by buying a drug testing kit and testing the drink before drinking it. 


\section{CONCLUSION}

Many of our most firmly held intuitions about procedural limits to consent's capacity to legitimise can be explained in terms of the no-gain and no-loss principles. The no-gain and no-loss principles, I have argued, explain why consent should be treated as ineffective when it is brought about by a violation or threatened violation of rights. By clarifying the various ways in which consent can be brought about by a violation or threatened violation of rights, we have been able to tidy up our intuitions about limits to consent's capacity to legitimise. The achievements of the no-gain and no-loss explanation of limits to consent's capacity to legitimise may be summarised as follows.

First, the explanation provides a clear endorsement of the widely held intuition that coerced consent is ineffective, and that the consent of an agent whose option set is restricted because of a past violation is also sometimes ineffective. It allows us to resolve the question, what types of threat render consent ineffective? According to the no-gain and no-loss explanation, threats can only render consent ineffective if they are threats to violate rights. Furthermore, the explanation allows us to understand why violations and threatened violations do not always render consent ineffective, only doing so if they restrict the agent's option set in an appropriate way, perhaps by eliminating all reasonable alternatives and thereby rendering the consent involuntary.

Second, the no-gain/no-loss approach explains the intuition that consent can be rendered ineffective by violations which alter agent's beliefs or prevent them from obtaining information that would stop them consenting. It can account for disagreement about whether the mere provision of false information or the withholding of true information can render consent ineffective. Such disagreement, the no-gain/no-loss 
approach suggests, is ultimately grounded in diverging views about what rights to information agents have.

Finally, the explanation fills the gap left by paternalist explanations in the case of incompetence. Paternalist explanations can explain the relatively uncertain intuition that the consent of incompetent agents in general is sometimes ineffective. But the no-gain and no-loss approach can explain the stronger intuition that consent is definitely ineffective when given by an agent who was rendered incompetent by a violation or threatened violation of his rights.

The implications of these findings are widespread. The conclusions about information and competence may be of particular interest to medical ethics, whilst the conclusions about coercive threats may be of interest to those concerned with rape law. Perhaps the findings will be of most general interest, however, to those concerned with the justice of market exchanges. For we are now equipped not only to insist that market exchanges brought about by a violation or threatened violation of rights should be treated as ineffective, but also to be much more precise about when market exchanges should be treated as ineffective for this reason. Even libertarians, with their otherwise scant moral framework, treat not only theft but also market exchanges bought about by a violation or threatened violation of rights as failing to preserve justice in transfer. The no-gain and no-loss principles, I have shown, can both justify this central part of the libertarian theory of justice and help us to understand its implications for the market. ${ }^{26}$ 


\footnotetext{
${ }^{1}$ The best argument for this view, as I have argued elsewhere, is that a plausible characterisation of consent and various aspects of the manner in which consent intuitively functions is only possible if the presence of an act is also necessary for consent.

${ }^{2}$ I use the term liberty in the sense of a Hohfelian privilege: one has a liberty to do something when one
} is not under a duty not to do that thing.

${ }^{3}$ There is no a priori reason why any particular instance of consent should not bring about a change in law even if the instance of consent brings about no corresponding change in morality. That consent often does bring about roughly corresponding changes in both morality and law is a reflection of the law's aspiration or need to conform to morality.

${ }^{4}$ On whether offers can coerce, see Joel Feinberg, Harm to Self (Oxford: Oxford University Press, 1986), ch. 24; Robert Nozick, 'Coercion', in Sidney Morgenbesser, Patrick Suppes and Morton Gabriel White, eds., Philosophy, Science and Method: Essays in Honor of Ernest Nagel, (New York: St. Martin's Press, 1969): 440-72; and Wertheimer, Coercion, ch. 13.

${ }^{5}$ C.f. Alan Carling, ‘Exploitation, Extortion and Oppression’, Political Studies 35 (1987): 173-88, at 184.

${ }^{6}$ David Hume, 'Of the Original Contract', in T. H. Green and T. H. Grose, eds., Essays: Moral, Political, and Literary, (London: Longmans, 1882), p. 451.

${ }^{7}$ E.g. Margaret Gilbert, 'Reconsidering the Actual Contract Theory of Political Obligation', Ethics 109 (1999): 236-60, at 240; A. D. Woozley, Law and Obedience: The Arguments of Plato's Crito (London: Duckworth, 1979), pp. 106-9.

${ }^{8}$ E.g. Luke Harding, 'Victim of Cannibal Agreed to be Eaten', The Guardian, $4^{\text {th }}$ December 2003, http://www.guardian.co.uk/world/2003/dec/04/germany.lukeharding

${ }^{9}$ There is one type of limit that does not fit comfortably into either of the two suggested categories procedural or substantive - but which deserves mention nevertheless. These are what Walzer calls blocked exchanges (Spheres of Justice: A Defense of Pluralism and Equality (New York: Basic Books, 1983), pp. 100-3). What makes blocked exchanges unique as a type of limit to consent's capacity to legitimise is their concern with the reason for which consent is given to a particular outcome, such as that one's consent is given in return for money or sex. Like Walzer, I do experience powerful intuitions to the effect that such 
exchanges should not be permitted. Nevertheless, I will not discuss the grounds for these intuitions, since they have already been well considered in existing scholarship, whereas the intuitions on which I will concentrate have not, I will argue, thus far received satisfactory treatment.

${ }^{10}$ Feinberg, Harm to Self, provides an argument which he describes as a 'soft paternalist' argument for limits to consent's capacity to legitimise associated with lack of choice and lack of information. However, Feinberg's soft paternalism does not appeal to benefit-based considerations, but rather to the value of autonomy and voluntariness. (Even Feinberg, pp. 12-6, admits that soft paternalism is not, unlike the benefit-based 'hard paternalism' discussed herein, paternalist in the proper sense of the word.) This allows Feinberg to argue that consent is sometimes rendered ineffective by the absence of choice or information because it is not sufficiently voluntary. I find this explanation implausible, because I see no reason to privilege autonomy over other values in explaining limits to consent's capacity to legitimise. More importantly, autonomy-based paternalism struggles just as much as benefits-based paternalism to explain the intuitive relevance of violations and threatened violations of rights to limits to consent's capacity to legitimise.

${ }^{11}$ Whatever our ultimate concern is, for practical purposes - for the purpose of implementing norms of compensation and rectification - we necessarily adopt a measure of gains and losses that is publicly discernable. To this end, we measure gains and losses in terms of market value where possible. Where this is not possible, for example in the case of bodily harms, we rely on courts to assess gains and losses by reference to well-established standards (which are, in turn, grounded in standardised assessments of what it would take to return an average agent to the same indifference curve), such that the value of nonmarketable gains and losses is also assessed in a manner roughly consistent across persons.

${ }^{12}$ Jules Coleman, Risks and Wrongs, (Oxford: Oxford University Press, 1992), ch. 16.

${ }^{13}$ Ernest J. Weinrib, 'Understanding Tort Law', Valparaiso Law Review 23 (1989): 485-526.

${ }^{14}$ These sets of limits might turn out to overlap, but they will not come into conflict with each other. To have a conflict we would need, for a particular instance of consent, both a reason to require that the consent be treated as ineffective and a reason to require that the consent be treated as effective. But the groundings in question only generate reasons to require that consent be treated as ineffective in a particular 
circumstance. They allow consent to be treated as effective in other circumstances, but they do not require it to be treated as effective in other circumstances.

${ }^{15}$ This might not be the end of the story. Compensation might also be payable, since the no-loss and nogain principles require that no loss or gain accrue relative to what the agents would have had, had the violation or threatened violation not taken place. For example, if the consent given as a result of a violation or threatened violation was consent to some exchange which replaced an alternative exchange (say, to purchase a similar item from a different agent at a cheaper price), then, if the alternative exchange can no longer be made (perhaps the other agent has now sold his item) the victim may be entitled to compensation for losing the opportunity to engage in the alternative exchange.

What if the victim received so much in return for his consent, and the perpetrator lost so much in return for the victim's consent, that the victim gained overall (relative to what he would have had without the violation or threat) and the perpetrator lost overall (relative to what he would have had without the violation or threat). Should we still treat such consent as ineffective? Perhaps not. But it will extremely rare that a violation brings about an act of consent that results in overall gains for the victim and overall losses for the perpetrator, since such outcomes would provide no motive for the perpetrator to perform or threaten the violation in the first place.

${ }^{16}$ Steiner's own explanation in terms of compossibility, the requirement that a set of rights must entail only obligations which can be conjunctively fulfilled, fails to demonstrate that consent in cases of liberal exploitation should be treated as ineffective. Steiner claims that if consent in such cases were treated as effective, just as if titles obtained by theft were treated as valid, then an incompossible set of rights would result. But this claim is wrong: the set of rights resulting from liberal exploitation would be entirely compossible. This is because in cases of theft, the original owner retains a title to the stolen items, so the thief cannot also have a title to the stolen items without violating compossibility; but in cases of liberal exploitation, if consent were treated as effective, the exploitee would no longer retain a title to the exploitatively obtained items, so the exploiter can gain a title without violating compossibility. Hillel Steiner, 'A Liberal Theory of Exploitation', Ethics 94 (1984): 225-41; Hillel Steiner, 'Exploitation: A 
Liberal Theory Amended, Defended and Extended', in Andrew Reeve, ed., Modern Theories of Exploitation (London: SAGE Publications, 1987), pp. 132-48.

${ }^{17}$ See, for example, H. L. A. Hart and Tony Honoré, Causation in the Law, $2^{\text {nd }}$ Edn. (Oxford: Clarendon Press, 1985), pp. 51-9.

${ }^{18}$ Ibid., p. 42.

${ }^{19}$ Ibid., p. 44.

${ }^{20}$ Note that the proposal here is not the same as Feinberg's proposal in Harm to Self, that consent is ineffective whenever it is involuntary. Whereas Feinberg is concerned about involuntariness for its own sake, the current proposal is only concerned about involuntariness insofar as it is relevant to determining whether or not consent was brought about by a violation or threatened violation. Hence the current proposal claims that involuntary consent is ineffective when it is brought about by a violation or threatened violation, but unlike Feinberg's proposal allows that involuntary consent be effective when it is not brought about by a violation or threatened violation.

${ }^{21}$ David Zimmerman, 'Coercive Wage Offers', Philosophy and Public Affairs 10 (1981): 121-45, at 124.

${ }^{22}$ Alan Wertheimer, Coercion (Princeton: Princeton University Press, 1987), pp. 267-74.

${ }^{23}$ Although it seems clear that a violation or threatened violation can bring about consent by altering an agent's beliefs or by preventing her obtaining relevant information, there are nevertheless difficulties, just as in the case of alternatives, in determining the limits of this relationship. For example, if a violation or threatened violation leaves an agent with a false belief, on the basis of which she subsequently consents, did the violation or threatened violation bring about her consent in the normatively relevant way, even if consenting was a crazy thing to do and would have been a crazy thing to do even if the belief had in fact been true? Did the violation or threatened violation render the consent involuntary?

${ }^{24}$ Paul Grice, Studies in the Way of Words (Cambridge, Mass.: Harvard University Press, 1989), p. 9.

${ }^{25}$ Rights to be given information are most plausibly thought to be held, in most cases, only against the recipient of consent, not against third parties. Rights against misinformation, on the other hand, are in many cases plausibly thought to be held against third parties as well as against the recipient of consent. But there are exceptions on both counts. Rights to information might plausibly be thought to be held against third 
parties in some situations. For example, a doctor might be thought to have duties of disclosure to a patient whom he is advising, even if the advice concerns the question, whether she ought to consent to some other doctor's performing an operation on her. Likewise, there are some situations in which rights against misinformation are only held against the recipient and not against third parties. For example, a buyer might plausibly be thought to have a right that a vendor not lie about a product which the buyer proposes to buy from him, but it seems less plausible that he has a right against the vendor's competitors that they not tell lies about the vendor's product.

${ }^{26}$ Libertarians, of course, claim not only that justice is not preserved when an exchange is brought about by a violation or threatened violation of rights, but also that justice is preserved (and that redistribution is illegitimate) when an exchange is not brought about by a violation or threatened violation of rights. The nogain and no-loss principles can justify the first claim, but they do not entail the second. They are entirely compatible with the existence of other principles that treat distributions of entitlements as unjust, and/or require redistribution of entitlements, for example to preserve equality or to meet basic needs. 